\title{
Comparison of dobutamine stress echocardiography with dipyridamole stress echocardiography for detection of viable myocardium after myocardial infarction treated with thrombolysis
}

Arnaldo Poli, Mario Previtali, Luca Lanzarini, Raffaela Fetiveau, Paolo Diotallevi, Maurizio Ferrario, Antonio Mussini, Giuseppe Specchia, Carlo Montemartini

\begin{abstract}
Objective-To compare the ability of dobutamine and dipyridamole stress echocardiography to detect functional recovery of stunned but viable myocardial regions early after acute myocardial infarction, and to predict late functional recovery of the reperfusion salvaged myocardium within the infarct area.

Methods-Within $10 \mathrm{~d}$ of acute myocardial infarction, 51 patients-30 anterior and 21 inferior, $44 Q$ wave and seven nonQ-wave infarction-were submitted to a dobutamine echocardiography test at low dose $(5-10 \mu \mathrm{g} / \mathrm{kg} / \mathrm{min}$ over $5 \mathrm{~min})$ and high dose $(20-40 \mu \mathrm{g} / \mathrm{kg} / \mathrm{min}$ over $3 \mathrm{~min})$ and to dipyridamole echocardiography test $(0.56 \mathrm{mg} / \mathrm{kg}$ over $4 \mathrm{~min}+0.28 \mathrm{mg} / \mathrm{kg}$ over $2 \mathrm{~min}$ ) on different days and in random order, after interruption of any vasoactive drug. Resting echocardiography was repeated at two months in 41 of 51 patients $(80 \%)$. Regional wall motion of the left ventricle was analysed in a semiquantitative manner on a 14-segment model. Viability was defined as improvement of one grade or more of at least two basally asynergic segments in the infarcted area.
\end{abstract}

Results-Regional functional recovery was detected by low dose dobutamine in $38 / 51$ patients $(75 \%)$ and in $147 / 308(48 \%)$ of basally asynergic segments, compared to $25 / 51$ patients $(49 \% ; P<0.001)$ and $78 / 308$ segments (25\%; $P<0.001)$ only identified by dipyridamole. Late spontaneous functional recovery was detected in $24 / 41$ patients $(59 \%)$ and in $78 / 254$ basally asynergic segments (31\%). The sensitivity of dobutamine and dipyridamole echocardiography for predicting spontaneous functional recovery was $72 \%$ and $51 \%$ respectively $(P<0.001)$, specificity $68 \%$ and $82 \%(P<0.001)$, positive predictive value $50 \%$ and $56 \%$, and negative predictive value $85 \%$ and $79 \%$.

Conclusions-In comparison with dipyridamole in patients with thrombolysed myocardial infarction, dobutamine induces regional functional recovery. This suggests that dobutamine is more sensitive in showing the presence of viable myocardium within the infarct zone, though it has a lower specificity in predicting delayed spontaneous functional recovery of non-contractile but still viable areas.

\section{(Heart 1996;75:240-246)}

Keywords: stress echocardiography; dobutamine; dipyridamole; myocardial infarction

Thrombolytic treatment has completely changed the natural history and prognosis of patients with acute myocardial infarction. The reduction of mortality observed in several randomised trials ${ }^{1-4}$ is principally the result of a limitation of the necrotic area and the preservation of left ventricular function obtained by the early recanalisation of the infarct related coronary artery. ${ }^{5-7}$ Therefore early identification of viable myocardium within the infarct zone could represent an important step in the prognostic evaluation and treatment of patients after myocardial infarction. Several studies have shown that after successful reperfusion of the ischaemic area the complete recovery of regional function can require a time period varying from few days to some months. ${ }^{8-10}$ Recent studies have shown that postischaemic dysfunction can be reversed either by direct inotropic stimulation with catecholamines infusion, ${ }^{1112}$ or by an increase in contractility mediated by an intense pharmacological vasodilatation of coronary bed. ${ }^{13} \mathrm{On}$ the basis of these experimental findings, low dose dobutamine and dipyridamole infusion combined with cross sectional echocardiography has been recently proposed for detection of non-contractile but viable areas after acute myocardial infarction. ${ }^{14-18}$ To date, however, no study has directly compared the accuracy of dobutamine and dipyridamole in identifying stunned but still viable myocardium in the infarct zone.

We therefore evaluated the ability of dobutamine and dipyridamole echocardiography to detect functional recovery suggesting the presence of myocardial viability within the infarct area in a population of patients with acute myocardial infarction treated with thrombolytic drugs. The acute response to both tests 
was correlated with late spontaneous functional recovery in the infarct area in order to assess whether dobutamine and dipyridamole echocardiography performed early after acute myocardial infarction could predict the improvement in wall motion abnormalities during the follow up.

\section{Methods \\ POPULATION}

From a population of 132 patients consecutively admitted (from January 1993 to March 1994) with a first acute myocardial infarction, diagnosed on the basis of typical chest pain lasting $>30 \mathrm{~min}$, increase in creatine kinase to at least twice the normal level, and $>1 \mathrm{~mm}$ evolutionary S-T elevation in at least two contiguous leads, 68 patients fulfilling the following criteria were initially selected for the study: (1) age $<70$ years, (2) treatment with thrombolytic drugs within $6 \mathrm{~h}$ from onset of chest pain, (3) no major in hospital complication, (4) no severe life limiting systemic disease, and (5) a good echocardiographic window under basal conditions. The reasons for the exclusion from the study were: age $>70$ years (25 patients), no thrombolytic treatment due to contraindication or late arrival in hospital (14 patients), major in hospital complication or death (15 patients), severe systemic disease (two patients), presence of a permanent pacemaker (two patients), or poor echocardiographic window under basal conditions (six patients). Seventeen patients who had a good echocardiographic window at baseline but showed a significant deterioration of images during dobutamine stress precluding a correct analysis of stress induced changes in wall motion, or in whom the same echocardiographic views were not available during both tests, were subsequently excluded. Therefore the final population of the study was 51 patients.

\section{STUDY DESIGN}

Within $10 \mathrm{~d}$ (mean 7 (SD 2) d) from the admission all patients underwent dobutamine and dipyridamole stress echocardiography in random order and on different days. $\beta$ Blockers, calcium antagonists, and nitrates were discontinued at least $48 \mathrm{~h}$ before the test.

\section{DOBUTAMINE ECHOCARDIOGRAPHY}

Dobutamine was infused starting with an initial dose of $5 \mu \mathrm{g} / \mathrm{kg} / \mathrm{min}$ for $5 \mathrm{~min}$ followed by a second dose of $10 \mu \mathrm{g} / \mathrm{kg} / \mathrm{min}$ over $5 \mathrm{~min}$ for detection of functional recovery in the infarct area (low dose dobutamine). In all patients, both the 5 and $10 \mu \mathrm{g}$ doses were examined for detection of improvement in regional function suggesting the presence of residual viable myocardium. Dobutamine infusion was then increased with incremental steps of 10 $\mu \mathrm{g} / \mathrm{kg} / \mathrm{min}$ every $3 \mathrm{~min}$ (high dose dobutamine) up to a maximum dose of $40 \mu \mathrm{g} / \mathrm{kg} / \mathrm{min}$ in order to assess the presence of residual ischaemia. The first eight patients of our population underwent low dose dobutamine only, because at that time insufficient data were available about the safety of high dose dobutamine performed early after acute myocardial infarction.

\section{DIPYRIDAMOLE ECHOCARDIOGRAPHY}

Dipyridamole was given with a first dose of $0.54 \mathrm{mg} / \mathrm{kg}$ over $4 \mathrm{~min}$, followed, in absence of an ischaemic response after $4 \mathrm{~min}$, by an additional dose of $0.28 \mathrm{mg} / \mathrm{kg}$ over $2 \mathrm{~min}$.

During the tests a 12-lead electrocardiogram recording was taken every minute and blood pressure was measured in basal conditions, and at the end of each step by cuff method. Cross sectional echocardiography was performed using a commercially available phased array imaging system (HewlettPackard model 77020 or Sonos 1000). Five standard views of the left ventricle (parasternal long axis and short axis views, apical four- and five-chamber and two-chamber views) were recorded, when possible, at baseline and during drug infusion. A test was prematurely interrupted when systolic arterial hypertension $(>220 \mathrm{~mm} \mathrm{Hg}$ ) or hypotension (defined as a decrease $>20 \mathrm{~mm} \mathrm{Hg}$ compared to the previous step), S-T segment elevation or depression $>2 \mathrm{~mm}$ compared to basal, severe angina, major ventricular arrhythmias, or any other untolerated side effect developed.

\section{ECHOCARDIOGRAPHIC ANALYSIS}

Cross sectional echocardiograms were recorded on videotape and analysed off line by two independent observers blinded to the clinical and angiographic data of the patients. In case of disagreement a consensus was reached. A 14-segment model of the left ventricle was used for the analysis of regional wall motion. ${ }^{19}$ Regional wall motion analysis was performed in a semiquantitative manner and each segment was scored as follows: $1=$ normal wall motion and systolic thickening; $2=$ hypokinesia (marked reduction in endocardial motion and systolic thickening); $3=$ akinesia (virtual absence of inward motion and systolic thickening); $4=$ dyskinesia (paradoxical wall motion away from the centre of the left ventricular in systole, or systolic thickening, or both). In order to correlate the regional wall motion abnormalities with the site of coronary lesions, we also defined the territory and segments perfused by the three major coronary vessels according to a previously described scheme. ${ }^{17}$ An asynergy wall motion score index defined as the sum of the scores assigned to each segment divided by the number of segments visualised was calculated in basal conditions, after low dose and high dose dobutamine, and after the first or second dose of dipyridamole. Functional recovery of the infarct area suggesting the presence of residual myocardial viability was considered to be significant when an improvement of contractility of one grade or more appeared in at least two basally hypokinetic or akinetic segments during low dose dobutamine infusion, or after the first or second dose of dipyridamole. Improvement of one segment was considered indicative of myocardial viability in patients showing only two basally abnormal segments. 
Table 1 Clinical and angiographic findings

\begin{tabular}{lc}
\hline Number of patients & 51 \\
Mean age (years) & $54(\mathrm{SD} 7)$ \\
Sex (M/F) & $48 / 3$ \\
Anterior AMI & $30(59 \%)$ \\
Inferior AMI & $21(41 \%)$ \\
Non-Q-wave AMI & $7(14 \%)$ \\
Time to thrombolysis (min) & $130(\mathrm{SD} 62)$ \\
Peak CK (mU/ml) & $2070(\mathrm{SD} 1298)$ \\
One-vessel disease & $40(78 \%)$ \\
Multivessel disease & $11(22 \%)$ \\
\hline AMI, acute myocardial infarction; CK, creatinine kinase.
\end{tabular}

To avoid the possible influence of the tethering effect on the interpretation of dobutamine or dipyridamole induced changes in the functional border zone, improvement in contraction extending for less than $1 \mathrm{~cm}$ at the boundary of the infarct zone was not considered indicative of improved function in the ischaemic area. ${ }^{15}$ The presence of residual ischaemia within the infarcted area was diagnosed when, during high dose dobutamine or after dipyridamole infusion, we observed: (1) a deterioration of contractility of basally hypokinetic segments, (2) a worsening of contractility of segments previously improved at lower doses of the drugs, or (3) a new asynergy of basally normal segments perfused by the infarct related artery.

\section{CORONARY ANGIOGRAPHY}

Within one month from myocardial infarction all patients underwent coronary angiography according to the Judkins technique. Right and left coronary arteries were evaluated by multiple views. In patients with multivessel disease, the infarct related coronary artery was identified by a correlation with electrocardiographic and echocardiographic findings. A significant coronary stenosis was defined as a $>50 \%$ narrowing of luminal diameter.

\section{FOLLOW UP}

A cross sectional echocardiographic control was performed at two months in 41 of 51 patients $(80 \%)$ in order to identify the spontaneous functional recovery of the infarct zone. Ten patients were treated with early coronary angioplasty and were therefore excluded from the follow up analysis.

\section{STATISTICAL ANALYSIS}

Changes of asynergy score index were analysed by paired $t$ test or, when appropriate, by analysis of variance (two way ANOvA) followed, when a statistically significant difference was found, by a multiple comparative test

Table 2 Coronary angiographic findings of the infarct related artery in patients with or without viability during dobutamine and dipyridamole stress tests

\begin{tabular}{lllll}
\hline & & \multicolumn{2}{l}{ Infarct related coronary artery } \\
\cline { 3 - 5 } & No of patients & Patent & Occluded & Occluded + CC \\
\hline Overall population & 51 & $43(84 \%)$ & $6(12 \%)$ & $2(4 \%)$ \\
$\begin{array}{l}\text { Dobutamine } \\
\quad \text { Viability }\end{array}$ & 38 & $35(92 \%)$ & $1(3 \%)$ & $2(5 \%)$ \\
$\quad$ No viability & 13 & $8(61 \%)$ & $5(39 \%)$ & $0(0 \%)$ \\
$\begin{array}{l}\text { Dipyridamole } \\
\quad \text { Viability }\end{array}$ & 25 & $23(92 \%)$ & $0(0 \%)$ & $2(8 \%)$ \\
$\quad$ No viability & 26 & $20(77 \%)$ & $6(23 \%)$ & $0(0 \%)$ \\
\hline
\end{tabular}

$\mathrm{CC}$, collateral circulation to the infarct related artery.
(Scheffé method). A $\chi^{2}$ test with Yates correction or a McNemar test was used, when appropriate, for comparison of categoric variables. All values are expressed as means (SD). A $P$ value $<0.05$ was considered significant.

\section{Results}

CLINICAL AND ANGIOGRAPHIC FINDINGS

Forty eight patients were men and three were women, with a mean age of 54 (SD 7) years (range 39-69). Myocardial infarction was anterior in 30 and inferior in 21 patients. Forty four (24 anterior and 20 inferior) were $Q$ wave and seven were non- $Q$-wave (six anterior and one inferior) myocardial infarcts. Forty patients were treated with alteplase $(100 \mathrm{mg}$ in $3 \mathrm{~h})$, eight with streptokinase (1500 $000 \mathrm{U}$ in $1 \mathrm{~h}$ ), and three with saruplase (bolus of $20 \mathrm{mg}$ followed by $60 \mathrm{mg}$ in $1 \mathrm{~h}$ ); thrombolytic treatment was started at a mean of $130(62) \mathrm{min}$ from onset of chest pain. Mean peak of creatine kinase was 2070 (1298) $\mathrm{mU} / \mathrm{ml}$ and appeared at a mean of $11(6) \mathrm{h}$ from the start of thrombolysis. All patients received aspirin and heparin infusion for at least $48 \mathrm{~h} ; \beta$ blockers and calcium antagonists were used when appropriate. At angiography 40 patients $(78 \%)$ had one-vessel disease and 11 patients $(22 \%)$, two- or three-vessel disease (table 1). The infarct related artery showed a $<50 \%$ stenosis in seven cases $(14 \%)$, a critical stenosis in 36 cases $(71 \%)$, and total occlusion in eight patients $(15 \%)$. Collaterals to the occluded artery were present in two of the eight patients $(25 \%)$ (table 2 ).

\section{ECHOCARDIOGRAPHIC ANALYSIS}

Two observers independently reviewed all echocardiographic stress tests, with an interobserver agreement of $90 \%(642 / 714 \mathrm{seg}-$ ments). One observer reviewed a random sample of 20 studies twice, with an intraobserver agreement of $96 \%$.

\section{DETECTION OF REGIONAL FUNCTIONAL}

\section{RECOVERY}

No significant changes in the baseline left ventricular wall motion score index were found between the two tests. Low dose dobutamine $(5-10 \mu \mathrm{g} / \mathrm{kg} / \mathrm{min})$ induced an improvement of contractility of the infarct area in $38 / 51(75 \%)$ patients in whom the mean left ventricular asynergy score index decreased from 1.66 $(0.34)$ to $1.37(0.30) \quad(P<0.001)$. In 13 patients $(25 \%)$ the asynergy score index did not change after low dose dobutamine $(1.78$ $(0.35) v 1.76(0.34)$, NS). Of the 308 basally asynergic segments, 147 (48\%) improved their function during dobutamine infusion. Twenty four of the 31 patients with functional recovery $(77 \%)$ developed residual ischaemia in the infarct area at high dose dobutamine.

Dipyridamole detected functional recovery of the infarct area in $25 / 51$ patients $(49 \%)$ in whom asynergy score index decreased from $1.65(0.38)$ to $1.43(0.36)(P<0.001)$. In the remaining 26 patients $(51 \%)$, dipyridamole did not induce any improvement within the infarcted zone and the mean asynergy score 
index did not modify $(1 \cdot 72(0.32)$ v 1.72 $(0 \cdot 32), \mathrm{NS})$. Of the 308 basally asynergic segments, $78(25 \%)$ showed a functional improvement after dipyridamole infusion. Twelve out of 25 patients with functional recovery $(48 \%)$ developed ischaemia in the infarct area during dipyridamole infusion.

Dobutamine and dipyridamole stress tests had concordant results for detection of regional functional recovery in $34 / 51$ patients (67\%), and $227 / 308$ segments $(74 \%)$ respectively; discordant results were observed in 17 patients $(33 \%)$ and 81 segments $(26 \%)$. The number of patients and segments showing functional recovery with low dose dobutamine was significantly higher compared to that obtained with dipyridamole infusion $(75 \% v$ $49 \%, \mathrm{P}<0.001$ and $47 \%$ v $25 \% ; \mathrm{P}<0.001)$.

SIDE EFFECTS

Dobutamine echocardiography was prematurely interrupted in one patient $(2 \%)$ who developed an increase of systolic blood pressure (> $220 \mathrm{~mm} \mathrm{Hg}$ ). Non-limiting side effects occurred in 11 patients (22\%): brief runs of slow ventricular tachycardia $(<10$ consecutive beats at a rate ranging from 90 to 120 beats $/ \mathrm{min}$ ) occurred in two patients (4\%), frequent premature ventricular beats in five $(10 \%)$, supraventricular arrhythmias in three $(6 \%)$, and hypotension occurred in one $(2 \%)$. During dipyridamole testing, minor side effects such as flushing and headache occurred in eight patients $(16 \%)$ and sporadic premature ventricular beats in three $(6 \%)$.

CORRELATION WITH ANGIOGRAPHIC FINDINGS Of the 38 patients showing myocardial viability with dobutamine, $37(97 \%)$ had either a patent infarct related coronary artery or an occlusion with collaterals, while only $8 / 13$ patients $(61 \%)$ without viability had a patent infarct related artery $(P<0.001)$. Also, for dipyridamole the percentage of patients with patency of the infarct related vessel was significantly higher in the group with than in the group without functional improvement of the infarct zone $(100 \% v 77 \%, \mathrm{P}<0.05)$ (table 2).

A critical stenosis of the infarct related artery was detected in $83 \%$ and $80 \%$ of the patients with functional recovery and residual ischaemia in the infarct area during dobutamine and dipyridamole infusion respectively.

\section{CORRELATION WITH LATE SPONTANEOUS FUNCTIONAL RECOVERY}

At two-month follow up, spontaneous functional recovery in the infarct area was found in $24 / 41$ patients $(59 \%) ; 78 / 254$ basally asynergic segments $(31 \%)$ showed an improvement of asynergy score of $\geqslant 1$ grade.

The 31 patients with regional functional recovery detected by low dose dobutamine showed a significant reduction of mean left ventricular asynergy score index from 1.67 $(0.36)$ to $1.4(0.31) \quad(P<0.05)$, while no improvement was observed in the 10 patients without functional recovery $(1.85(0.36) v$ $1.84(0 \cdot 4)$, NS). Twenty out of $31(64 \%)$

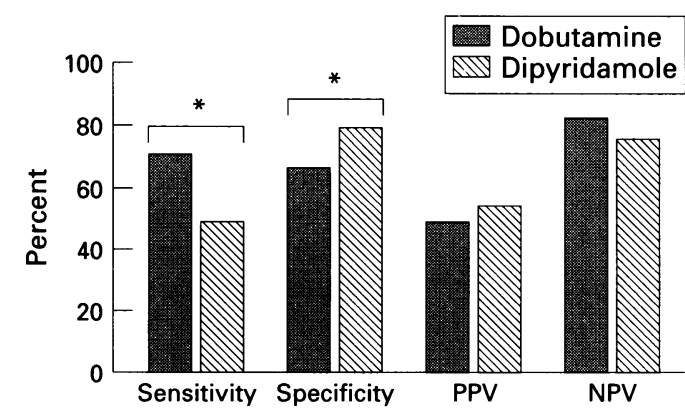

Sensitivity, specificity, positive predictive value, and negative predictive value of dobutamine and dipyridamole echocardiography in predicting spontaneous functional recovery of the asynergic regions at follow up. PPV, positive predictive value; NPV, negative predictive value. * $P<0.001$.

with, but only $1 / 10$ patients (10\%) without, dobutamine induced functional recovery in the infarct area showed an improvement in regional wall motion abnormalities at follow up. Dobutamine correctly identified 56/78 segments showing late spontaneous functional recovery (sensitivity $72 \%$ ) and $120 / 176$ segments without improvement of contractility at follow up (specificity $68 \%$ ). Positive and negative predictive value of dobutamine echocardiography for late spontaneous functional recovery were $50 \%$ and $85 \%$ respectively (figure). Among the patients with dobutamine induced functional recovery, all seven with no residual ischaemia in the infarct zone showed an improvement in regional contractility, while only $13 / 20$ patients $(65 \%)$ with inducible ischaemia did so $(P<0.001)$.

At two-month follow up, the 21 patients with dipyridamole induced functional recovery showed a significant reduction of mean asynergy score index, from $1.67(0.38)$ to 1.45 $(0.37)(P<0.05)$; however, an improvement in the asynergy score index from $1.76(0.34)$ to $1.66(0.45)(P<0.05)$ was also observed in the 20 patients with no evidence of functional recovery in the infarct zone with dipyridamole echocardiography. Fourteen out of 21 patients with $(67 \%)$, and $8 / 20(40 \%)$ patients without, dipyridamole induced functional recovery showed an improvement of regional contractility at follow up. Dipyridamole correctly identified 40 of 78 segments with late spontaneous functional recovery (sensitivity $51 \%$ ) and 145 of 176 segments without improvement at follow up (specificity $82 \%$ ). Positive and negative predictive values for late spontaneous recovery were $56 \%$ and $79 \%$ respectively (figure). At follow up 8/11 (73\%) patients showing functional recovery and no inducible ischaemia during dipyridamole infusion had a spontaneous contractile improvement compared to $6 / 10$ patients $(60 \%)$ with dipyridamole induced functional recovery and ischaemia in the infarct area (NS).

\section{Discussion}

DETECTION OF REGIONAL FUNCTIONAL

RECOVERY

In acute myocardial infarction, the myocardium salvaged by successful thrombolysis 
may show a prolonged postischaemic contractile depression that may prevent its early identification within the infarcted area. ${ }^{8-10}$ The use of dobutamine and dipyridamole stress echocardiography for detection of viability is based on experimental and clinical observations showing that postischaemic wall motion abnormalities can be reversed by inotropic stimulation by catecolamines or by vasodilators $^{11-13}$ and that changes in regional contractility may be easily detected by cross sectional echocardiography. ${ }^{14-18}$ Dobutamine exerts a direct inotropic effect by interaction with cardiac $\beta$ receptors. ${ }^{112}$ The mechanisms by which dipyridamole can induce an increment in myocardial contractility of stunned myocardium are not completely understood. The most likely mechanism is the dipyridamole induced increase in blood flow and vascular volume within the ventricular wall of the stunned segments, which in turn leads to a stretching of myocardial fibres and to an increase in contractility through the FrankStarling effect. In experimental animals subjected to repeated brief coronary occlusion a $150 \%$ increase in baseline regional blood flow of stunned myocardium induced by dipyridamole was associated with a $8 \cdot 8 \%$ increase in segmental shortening. ${ }^{13}$ Other possible mechanisms are sympathetic activation secondary to the systemic vasodilatation or a decrease of ventricular afterload. ${ }^{131820}$ Piérard et $a l^{15}$ showed that, in patients with myocardial infarction, low dose dobutamine may determine some functional recovery of myocardial segments showing persistent metabolic activity on positron emission tomography. Furthermore, in patients with previous myocardial infarction, Picano et al recently observed a good concordance between dipyridamole stress echocardiography and rest thallium scintigraphy in detecting viable myocardial areas. ${ }^{18}$ No study, however, has directly compared the ability of dobutamine and dipyridamole stress echocardiography to identify stunned but still viable myocardium in the infarcted zone. In our study, detection of viable myocardium either by dobutamine or dipyridamole was strictly associated with the patency of the infarct related artery or the presence of collateral circulation to the occluded artery, which were shown to be a requisite for preservation of myocardial viability in the infarcted area. ${ }^{151821}$ This correlation could also explain the results of several studies showing that patency of the infarct related coronary artery is a major determinant of left ventricular function and prognosis after acute myocardial infarction. ${ }^{22-24}$ Compared with dipyridamole, dobutamine detected regional functional recovery in a greater number of patients and segments. This finding can be explained by the fact that at low doses dobutamine improves myocardial contractility in the asynergic regions by a direct inotropic effect which does not significantly affect myocardial oxygen demand and consequently is not critically dependent upon an increase in coronary blood flow. On the other hand, the ability of dipyridamole to improve wall motion abnor- malities by increasing regional blood flow in the infarct related artery can be significantly conditioned by the severity of residual stenosis and consequent reduction of coronary flow reserve. This hypothesis is supported by the observation that, in our population, dipyridamole echocardiography showed regional functional recovery in six out of seven patients (85\%) without, but only in 20 out of 38 patients $(52 \%)$ with, critical lesions of the infarct related vessel.

It has been shown that dobutamine can improve myocardial thickening of nonischaemic but asynergic myocardium adjacent to necrotic tissue, inducing a reduction of the size of the functional border zone. ${ }^{25}$ This phenomenon could determine an overestimation of the extension of non-contractile but still viable regions. To avoid such misinterpretation, in line with other experimental and clinical studies we therefore excluded from the analysis any improvement in contractility extending for less than $1 \mathrm{~cm}$ at the boundary of the infarct area..$^{1526}$

\section{CORRELATION WITH LATE SPONTANEOUS} FUNCTIONAL RECOVERY

Recovery of postischaemic regional dysfunction is dependent on the presence of a patent coronary artery and on the restoration of adequate perfusion of asynergic segments. ${ }^{152728}$ Piérard et $a l^{15}$ showed that recovery of contractility is more frequent in viable myocardial segments in which normal perfusion is detected at positron emission tomography. Picano et al also observed a significant correlation among dipyridamole detected viability, preserved perfusion of viable segments during rest thallium scintigraphy, and late functional recovery..$^{18}$ In our study, patients with residual viable myocardium identified by dobutamine or dipyridamole echocardiography showed a significant spontaneous improvement of regional wall motion abnormalities at the two months follow up. Conversely, among the patients with no residual myocardial viability in the infarct zone, the group identified by dobutamine did not show any significant functional recovery at follow up, while the group detected by dipyridamole had a reduction in mean asynergy score index. These data suggest that dipyridamole was unable to induce regional functional recovery in a significant number of patients with viable myocardium and explain its lower sensitivity (51\%) compared to that of dobutamine $(72 \%)$ in predicting late functional recovery. On the other hand, specificity was higher for dipyridamole echocardiography $(82 \%)$ than for dobutamine echocardiography (68\%). A possible explanation is that dipyridamole improves contractility of myocardial segments where there is less severe stenosis of the infarct related artery and less compromised perfusion, and which are therefore more likely to recover spontaneously. ${ }^{15}$ The relatively low specificity of dobutamine echocardiography for predicting functional recovery can also be explained by the fact that we evaluated spontaneous functional recovery; it would be probably higher if 
the patients were studied after myocardial revascularisation by coronary angioplasty or bypass grafting, as observed by other investigators. ${ }^{14}$ In our study, specificity of dipyridamole echocardiography was similar but sensitivity lower than that obtained by Picano et $a l^{18}$; however, their patients were studied after a mean of 3.5 months from the acute phase of myocardial infarction and the follow up period was also longer than in our population.

\section{SIGNIFICANCE OF DETECTION OF RESIDUAL} MYOCARDIAL ISCHAEMIA

In the population studied, detection of myocardial viability was frequently associated with residual ischaemia in the infarct area identified by a deterioration of contractility following a transitory improvement of wall motion abnormalities during dobutamine or dipyridamole infusion. Dobutamine echocardiography detected residual ischaemia in the viable regions in a larger number of patients than dipyridamole echocardiography; however, the demonstration of ischaemia was highly predictive of the presence of an angiographically critical stenosis of the infarct related vessel with both tests. Patients showing this pattern of response had a less frequent functional recovery at follow up than those with viability and no residual ischaemia. It is possible to hypothesise that the presence of a critical stenosis of the infarct related coronary artery may induce a chronic hypoperfusion or recurrent episodes of ischaemia that limit or even impede spontaneous improvement of viable but non-contractile regions. ${ }^{28-30}$ Likewise it is possible that this condition may be corrected by successful recanalisation of the infarct related vessel by coronary angioplasty or bypass grafting. ${ }^{14} 18$

\section{STUDY LIMITATIONS}

A limitation of the study may be the selection criteria of the patient population. The results we obtained in this group of patients with a first, uncomplicated myocardial infarction treated with thrombolysis cannot be extended to the general population of patients with myocardial infarction. It is likely that the prevalence of myocardial viability and ischaemia detected by dobutamine and dipyridamole would be different in a higher risk population of patients with non-thrombolysed or complicated myocardial infarction, reinfarction, or a high prevalence of multivessel coronary artery disease. Another limitation could be that our two-month echocardiographic follow up cannot be considered sufficient to fully estimate the extent of spontaneous delayed functional recovery. In fact, Galli et al recently showed that a significant improvement of perfusion and function in the infarcted area may occur as late as seven months after the acute phase. ${ }^{30}$ Thus the reported sensitivity and specificity for predicting spontaneous functional recovery would be probably different if evaluated during a longer follow up period.

CLINICAL IMPLICATIONS

In patients with recent myocardial infarction treated with thrombolytic drugs, detection of regional functional recovery within the infarct area by stress echocardiography is well correlated with patency of the infarct related coronary artery and late spontaneous functional recovery. Compared with dipyridamole, dobutamine echocardiography identifies functional recovery, suggesting the presence of myocardial viability in a greater number of patients, and shows a higher sensitivity but a lower specificity in predicting spontaneous functional recovery of the infarct area. The clinical usefulness of early identification of myocardial viability with stress echocardiography is not well established and further studies are needed to assess its prognostic significance on the long term evolution of left ventricular function. The clinical importance of early detection of viable myocardium by stress echocardiography is mainly related to the fact that viability in the infarct zone is frequently associated with residual myocardial ischaemia caused by the presence of a critical coronary stenosis, which may prevent spontaneous contractile recovery. As for viability identification, dobutamine echocardiography detects residual ischaemia in the infarct area more frequently than dipyridamole echocardiography and therefore seem to be superior in identifying viable but jeopardised myocardial regions. Further studies are needed to assess whether this difference may have clinical significance in predicting recurrent ischaemic events and functional improvement of the infarct area after revascularisation procedures.

1 Gruppo Italiano per lo Studio della Streptochinas nell'Infarto Miocardico (GISSI): Effectiveness of intravenous thrombolytic treatment in acute myocardial infarction. Lancet 1986;i:397-401.

2 ISIS-2 (Second International Study of Infarct Survival) Collaborative Group. Randomised trial of intravenous 17,187 cases of suspected acute myocardial infarction: ISIS-2. Lancet 1988;ii:349-60.

3 Simoons ML, Serruys PW, Brand M, et al. Improved survival after early thrombolysis in acute myocardial infarction: a randomized trial by the Interuniversity Cardiology tion: a randomized trial by the Interuniversity Cardiology Institute in The Netherlands. Lancet 1985;ii:578-82.

4 White HD, Norris RM, Brown MA, et al. Effect of intravenous streptokinase on left ventricular function and early survival after acute myocardial infarction. $N$ Engl $\mathfrak{F}$ Med 1987;317:850-5.

5 Serruys PW, Simoons ML, Suryapranata $\mathrm{H}$, et al. Preservation of global and regional left ventricular function after early thrombolysis in acute myocardial infarction. $\mathcal{F}$ Am Coll Cardiol 1986;7:729-42.

6 O'Rourke M, Baron D, Keogh A, et al. Limitation of myocardial infarction by early infusion of recombinan tissue-type plasminogen activator. Circulation 1988;77: 1311-5.

7 Yusuf S, Sleight P, Held P, MacMahon S. Routine medical management of acute myocardial infarction: lesson from management of acute myocardial infarction: lesson from Circulation 1990;82(suppl II):II-117-34.

8 Ellis SG, Henschke CI, Sandor T, Wynne J, Braunwald E Kloner RA. Time course of functional and biochemical recovery of myocardium salvaged by reperfusion. $\mathcal{f} \mathrm{Am}$ recovery of myocardium sal Cardiol 1983;1:1047-55.

9 Braunwald E, Kloner RA. The stunned myocardium: prolonged, postischemic ventricular dysfunction. Circulation 1982;66:1146-9.

10 Picard MH, Wilkins GT, Ray PA, Weyman AE. Long-term effects of acute thrombolytic therapy on ventricular size and function. Am Heart $\mathcal{F}$ 1993;126:1-10.

11 Bolli R, Zhu WX, Myers ML, Hartley CJ, Roberts R. Betaadrenergic stimulation reverses postischemic myocardial dysfunction without producing subsequent functional deterioration. $\mathrm{Am} 7 \mathrm{C}$ Cardiol 1985;56:964-8.

12 Ellis SG, Wynne J, Braunwald E, Henschke CI, Sandor T Kloner RA. Response of reperfusion-salvaged, stunned myocardium to inotropic stimulation. Am Heart $f$ 1984;107:13-9.

13 Stahl LD, Aversano TR, Becker LC. Selective enhancement of function of stunned myocardium by increased flow. Circulation 1986;74:843-51. 
14 Barilla F, Gheorghiade M, Alam M, Khaja F, Goldstein S. Low-dose dobutamine in patients with acute myocardial
infarction identifies viable but not contractile infarction identifies viable but not contractile myocardium and predicts the magnitude of improvement revascularisation. Am Heart f 1991;112:1522-31.

15 Piérard LA, De Landsheere CM, Berthe C, Rigo $P$, Kulbertus HE. Identification of viable myocardium by echocardiography during dobutamine infusion in patients with myocardial infarction after thrombolytic therapy: comparison with positron emission tomography. $\mathcal{f} A m$ Coll Cardiol 1990;15:1021-31.

16 Smart SC, Sawada S, Ryan T, et al. Low-dose dobutamine echocardiography detects reversible dysfunction after thrombolytic therapy of acute myocardial infarction. Circulation 1993;88:405-15.

17 Previtali M, Poli A, Lanzarini L, Fetiveau R, Mussini A Ferrario M. Dobutamine stress echocardiography for assessment of myocardial viability and ischemia in acute myocardial infarction treated with thrombolysis. $A m \mathcal{F}$ myocardial infarction treat

18 Picano E, Marzullo P, Gigli G, et al. Identification of viable myocardium by dipyridamole-induced improvement in regional left ventricular function assessed by echocardiog raphy in myocardial infarction and comparison with thal-

19 Edwards WD, Tajik AJ, Seward JB. Standardized nomenclature and Tajik AJ, Seward JB. Standardized nomenanalysis of the heart. Mayo Clin Proc 1981;56:479-97.

20 Lucarini AR, Picano E, Marini C, Favilla S, Salvetti A Distante A. Activation of sympathetic tone during dipyridamole test. Chest 1992;102:444-7.

21 Bolognese L, Sarasso G, Bongo A, et al. Dipyridamole echocardiography test. A new tool for detecting jeopardized myocardium after thrombolytic therapy. Circulation 1991;84:1100-6.
22 Braunwald E. Myocardial reperfusion, limitation of infarct size, reduction of left ventricular dysfunction, and
improved survival: Should the paradigm be expanded? improved survival: Should
Circulation 1989;79:441-4.

23 Topol EJ, Califf RM, George BS, Kereiakes DJ, Lee KL for the TAMI Study Group. Insights derived from the Thrombolysis and Angioplasty in Myocardial Infarction (TAMI) Trial. F Am Coll Cardiol 1988;12:24-31A.

24 Stadius ML, Davis K, Maynard C. Risk stratification for 1 year survival based on characteristics identified in the early hours of acute myocardial infarction. Circulation 1986;74:703-10.

25 Buda AJ, Zotz RJ, Gallagher KP. Characterization of the functional border zone around regionally ischemic myocardium using circumferential flow-function maps. $\mathscr{f}$ Am Coll Cardiol 1986;8:150-8.

26 Gallagher KP, Gerren RA, Stirling MC, Choy M, Dysko RC, McManimon SP, Dunham WR. The distribution of functional impairment across the lateral border of acutely ischemic myocardium. Circ Res 1986;58:570.

27 Leung W-H, Lau C-P. Effects of severity of the residual stenosis of the infarct-related coronary artery on left venstenosis of the infarct-related coronary artery on left ven-
tricular dilatation and function after acute myocardial tricular dilatation and function after acute

28 Luciano Agat, Paolo Voci, Federico Bilotta, et al. Influence of residual perfusion within the infarct zone on the natural history of left ventricular dysfunction after acute myocardial infarction: a myocardial contrast echocardiographic study. $\mathcal{A}$ Am Coll Cardiol 1994;24:336-42.

29 Rahimtoola SH. The hibernating myocardium. Am Heart $\mathfrak{f}$ 1989;117:211-20.

30 Galli M, Marcassa C, Bolli R, et al. Spontaneous delayed recovery of perfusion and contraction after the first 5 weeks after anterior infarction. Evidence for the presence of hibernating myocardium in the infarct area. Circulation 1994;90:1386-97. 